\title{
Electrochemically Driven Interfacial Halogen Bonding on Self- Assembled Monolayers for Anion Detection
}

\author{
Hussein Hijazi, ${ }^{a}$ Antoine Vacher, ${ }^{\mathrm{b}}$ Sihem Groni, ${ }^{a}$ Dominique Lorcy, ${ }^{\mathrm{b}}$ Eric Levillain, ${ }^{\mathrm{c}}$ Claire Fave ${ }^{* a}$ and \\ Bernd Schöllhorn*a
}

\begin{abstract}
Electrochemically driven interfacial halogen bonding between redox-active SAMs and halide anions was quantitatively studied for the first time. The halogen bond donor properties were switched on by electrochemically controlling the oxidation state of the adsorbates. Experimental data and simulation show high binding enhancement towards halide anions compared to homogeneous systems.
\end{abstract}

Without doubt, self-assembled monolayers (SAMs) are one of the best systems for studying the structure-reactivity relationship of surface confined molecules at the solid/liquid interface. $^{1}$ Over the past decade a plethora of SAMs applications have been extensively explored in fields such as wettability, recognition, sensing and catalysis..$^{1-4}$ While numerous results have been obtained for ion recognition in homogeneous solution, ${ }^{4}$ the combination of molecular receptors and SAMs should generate an amplification of the recognition process (faster response, easier reproducibility...) at the monolayer/solution interface ${ }^{5}$ due to the preorganization of receptors on the surfaces. ${ }^{2,6}$ Non-covalent interactions are key parameters for recognition with a stronger effect at the interface than in solution. ${ }^{7}$ Among weak interactions, Halogen bonding $(X B)^{8}$ is becoming more and more popular to control supramolecular recognition in solution. ${ }^{9} \mathrm{XB}$ is a net attractive interaction occurring between the electrophilic site $(\sigma \text {-hole })^{10}$ of a bound halogen atom and a nucleophilic Lewis base. Due to strong directionality, XB interactions are excellent candidates for molecular receptors and their use may lead to numerous potential applications for

\footnotetext{
a. Laboratoire d'Electrochimie Moléculaire, UMR CNRS 7591, Université Paris

Diderot, Sorbonne Paris Cité, 15 rue Jean-Antoine de Baï, F-75205 Paris Cedex 13, France.

b. Université Rennes, CNRS, ISCR Institut des Sciences Chimiques de Rennes - UMR 6226, F-35000 Rennes, France.

MOLTECH-Anjou. UMR CNRS 6200 -Université d'Angers -2 Bd Lavoisier, F-49000 Angers, France.

${ }^{+}$Electronic Supplementary Information (ESI) available: General procedures as well as data and data plots, such as the corresponding CVs and absorption spectra. See DOI: $10.1039 / x 0 x x 00000 x$
}

interfacial systems. However up to date XB remains scarcely explored at the interface and only few systems have been described so far using either STM, AFM, ${ }^{11} \mathrm{SPR}^{12,13} \mathrm{TEM}^{14}$ or even Transient absorption spectroscopy. ${ }^{15}$ Recently, we have demonstrated the potential of electrochemistry as a powerful technique to detect and to control $X B$ in solution. Cyclic voltammetry is an economical, simple but precisely controllable tool well adapted for the investigation of such weak interactions in solution. Electrochemical activation of either redox-active $X B$ acceptors $^{16}$ or $X B$ donors $17,18,19$ showed significant and reversible $X B$ binding enhancement upon electrochemical manipulation.

Our study aims at transferring this concept from homogeneous solution to the interface of a conductive material. Tetrathiafulvalene (TTF) derivatives display many advantages and are therefore a suitable choice for transferring the concept onto the surface. In literature TTF based SAMs with cation recognition ${ }^{20}$ have been described but to the best of our knowledge never for anion detection.

Here we describe for the first time electrochemically driven interfacial XB formation between redox-active SAMs and halide anions in solution with a high binding enhancement. The ability to detect halides such as chloride and bromide is crucial in many aspects of medicine, industrial processes and environmental analyses. Chloride is a key indicator of fecal contamination in the environment, while bromide is used in medicine. ${ }^{21}$

Recently we demonstrated the decisive role of the anchoring group on the formation and the stability of $\mathrm{SAMs}^{22}$ and thus chose thioctic acid derivatives bearing TTF groups for the

Scheme 1. Synthesis of compounds $\mathbf{1 a}$ and $\mathbf{1 b}$

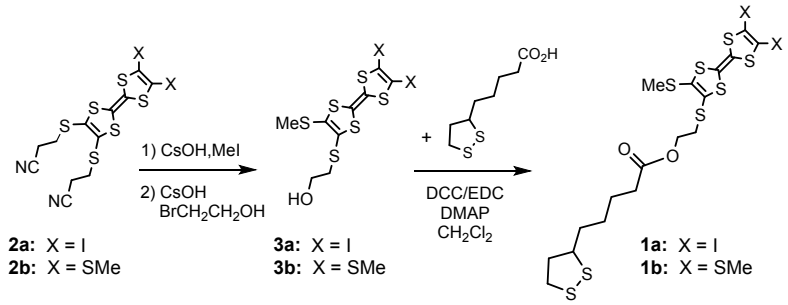


chemisorption onto gold electrodes. Two TTF containing adsorbates 1a and 1b have been studied (Scheme 1). 1a was synthesized from the dissymmetrical TTF derivative $2 a{ }^{23}$ We also prepared a reference TTF derivative, $\mathbf{1 b}$, in which the two iodine atoms were replaced by methylthio substituents, starting from the precursor $\mathbf{2} \mathbf{b} .{ }^{24}$ Compounds $\mathbf{2} \mathbf{a}-\mathbf{b}$ are substituted on one side by two cyanoethylthio groups which can lead under basic conditions to the corresponding dithiolates. ${ }^{25}$ When employing one equivalent of cesium hydroxide followed sequentially by the addition of iodomethane, a second equivalent of base and then 2-bromo-ethanol, TTF 3 a was obtained. According to the same sequential procedure, $\mathbf{3 b}^{24}$ was synthesized from $\mathbf{2} \mathbf{b}$. Adsorbates $\mathbf{1} \mathbf{a}-\mathbf{b}$ were prepared by esterification of the respective parent alcohols $\mathbf{3} \mathbf{a}-\mathbf{b}$ with commercially available thioctic acid.

Acetonitrile (ACN) has been identified as a well-adapted solvent for the characterization of the SAMs while compounds 1a and 1b showed a better solubility in 30\% ACN/DMF containing 0.1 $\mathrm{M}$ tetrabutylammonium hexafluorophosphate $\left(\mathrm{NBu}_{4} \mathrm{PF}_{6}\right)$ as supporting electrolyte. CVs of both compounds showed two reversible single-electron oxidation waves with standard potentials (Vs. SCE) of $+0.64 \mathrm{~V}$ and $+0.83 \mathrm{~V}$ for compound $1 \mathrm{a}$ and $+0.59 \vee$ and $+0.77 \vee$ for $\mathbf{1 b}$ (Table 1 and Fig.S1, see $\mathrm{ESI}^{\dagger}$ ). Furthermore both compounds show two irreversible peaks at relatively high anodic and cathodic potentials of $+1.17 \mathrm{~V} /+1.09$ $\mathrm{V}\left(E_{\mathrm{PA}(\mathrm{S}-\mathrm{s})}\right)$ and $-\mathbf{2 . 1 7} /-2.03 \mathrm{~V}\left(E_{\mathrm{PC}(\mathrm{S}-\mathrm{s})}\right)$ respectively for $\mathbf{1} \mathbf{a}$ and $\mathbf{1 b}$, characteristic of the reductive and oxidative cleavage of the disulphide bond. For 1a, two supplementary cathodic irreversible waves at -1.19 and $-1.39 \mathrm{~V}$ were recorded and can be attributed to the dissociative reduction of the $\mathrm{C}-\mathrm{I}$ bonds.

Halide anions (Lewis Bases) proved to be strong XB acceptors in the presence of iodo-TTF ${ }^{+}$cation radicals. ${ }^{17}$ Upon the addition of $\mathrm{Cl}^{-}$as tetrabutylammonium chloride $\left(\mathrm{NBu}_{4} \mathrm{Cl}\right)$ the first oxidation wave shifted significantly to lower potentials $\left(\Delta E^{\circ \prime}{ }_{1}=\right.$ $55 \mathrm{mV}$ for 50 equiv. of $\mathrm{Cl}^{-}$) indicating the formation of a XB complex with the radical cation of 1 a (Fig.S4A, see $\mathrm{ESI}^{+}$).

Such behaviour can be attributed to a substantial stabilization of the cation through $\mathrm{XB}$ interaction with the anion and has recently been proven in the case of iodo- and (Me) ${ }_{3}$-iodo-TTF. ${ }^{17}$ In contrast, reference compound $\mathbf{1 b}$ did not show any potential shift (Fig.S4, see $\mathrm{ESI}^{+}$). In order to validate the predominant XB interaction with $\mathrm{Cl}^{-}$, we also studied the electrochemical behaviour of the precursor alcohols (Scheme 1) $\mathbf{3 a}$ and $\mathbf{3 b}$. As expected, in contrast to $\mathbf{3 b}$, $\mathbf{3} \mathbf{a}$ showed a similar potential shift behaviour as compound 1a (Fig.S5, see $\mathrm{ESI}^{+}$). After addition of 100 equivalents of $\mathrm{NBu}_{4} \mathrm{Cl}$ in solution, comparable shifts for the first wave have been obtained ( $84 \mathrm{mV}$ for $\mathbf{3 a}$ and $78 \mathrm{mV}$ for $\mathbf{1 a}$, Fig.S6, see $\left.\mathrm{ESI}^{+}\right)$. The corresponding affinity constants $K_{\text {red }}$ (between the anion and the neutral state of the TTF) and $K_{\text {ox }}$ (between the anion and the radical cation state of the TTF) were determined by fitting the experimental titration curves (see $\mathrm{ESI}^{+}$). Both compounds present similar affinity constant leading to $K_{\mathrm{ox}}=800 \mathrm{M}^{-1}$ for $1 \mathrm{a}$, and to $K_{\mathrm{ox}}=1200 \mathrm{M}^{-1}$ for $3 \mathrm{a}$ illustrating the importance of the $X B$ donor strength. In fact we have previously reported two to three times lower $K_{\mathrm{ox}}$ for mono iodoTTF derivatives toward $\mathrm{Cl}^{-}$.
Table 1. Electrochemical data for compounds $\mathbf{1 a}$ and $\mathbf{1 b}$

\begin{tabular}{ccccc}
\hline \multicolumn{2}{c}{ Solution $^{[\mathrm{a}]}$} & \multicolumn{2}{c}{ SAMs ${ }^{[\mathrm{b}]}$} \\
\hline & $\mathbf{1 a}$ & $\mathbf{1 b}$ & SAM-1a & SAM-1b \\
\hline$E^{\mathrm{o} \prime}{ }_{1}{ }^{[\mathrm{c}]}$ & +0.64 & +0.59 & +0.72 & +0.58 \\
$E^{\mathrm{o}}{ }_{2}{ }^{[\mathrm{c}]}$ & +0.83 & +0.77 & +0.98 & +0.89 \\
$E_{\mathrm{PA}(\mathrm{S}-\mathrm{S})^{[\mathrm{c}]}}$ & +1.17 & +1.09 & & \\
$E_{\mathrm{PC}\left(\mathrm{S}-\mathrm{S}{ }^{[\mathrm{c}]}\right.}$ & -2.17 & -2.03 & & \\
$E_{\mathrm{PC}(\mathrm{C}-1)}{ }^{[\mathrm{c}]}$ & $-1.19 /-1.39$ & & & \\
$\mathrm{D}^{[\mathrm{d}]}$ & 1.56 & 1.93 & & \\
$\Gamma^{[\mathrm{e}]}$ & & & $1.45 \pm 0.07$ & $1.94 \pm 0.15$
\end{tabular}

[a] in $30 \%$ ACN / 70\% DMF. [b] in ACN. [c] in V, vs. SCE. [d] Diffusion coefficient in $10^{-6} \mathrm{~mol} . \mathrm{cm}^{-2}$ [e] Surface coverage in $10^{-10} \mathrm{~mol}_{\mathrm{cm}} \mathrm{cm}^{-2}$.

The presence of two iodine substituents in $\mathbf{1 a}$ and $\mathbf{3 a}$ is likely responsible for the increase of the $X B$ donor strength. As expected, $K_{\text {red }}$ values are negligible and cannot be determined precisely. The $K_{\text {ox }} / K_{\text {red }}$ ratios represent the most reliable values for an estimation of the relative binding enhancement upon oxidation and are indicated in Table 2. After rinsing of the resulting modified electrodes (see $\mathrm{ESI}^{+}$for details), SAM-1a and SAM-1b, CVs were conducted in pure $0.1 \mathrm{M} \mathrm{n}-\mathrm{Bu}_{4} \mathrm{PF}_{6} / \mathrm{ACN}$ (Fig.1). SAM-1a and SAM-1b display two distinct oxidation peaks having the characteristic features of surface confined redox centres: decreased capacitive current (Fig.1); linear dependence of peak currents with the scan rate (Fig.S7, see $\mathrm{ESI}^{+}$). These results provide evidence of a non-diffusional system with the redox moieties attached to the surface. Assuming that the two oxidation peaks are corresponding to two successive one-electron processes as for homogeneous solution, the integration of the signals allowed estimating the surface coverage of the electrode, leading to $1.5 \cdot 10^{-10} \mathrm{~mol}^{-\mathrm{cm}^{-2}}$ for SAM-1a and $1.9 \cdot 10^{-10} \mathrm{~mol}^{-\mathrm{cm}^{-2}}$ for SAM-1b, values matching with relatively dense TTF mono-layers. ${ }^{26}$ It is notable that the peak shapes were significantly sharper and much more symmetrical for SAM-1b as a results of the beneficial effect of the thiomethyl group.

The detection of the XB formation on TTF-SAMs has been performed on the first peak corresponding to the formation of the radical cation due to better stability in this potential window. ${ }^{20 a, 22 a}$ The first oxidation wave of SAM-1a was strongly affected in the presence of chloride contrary to SAM-1b. With SAM-1a the oxidation peak progressively decreases to negative potential upon raising the chloride concentration (Fig.2A). Simultaneously a new wave emerged at lower potential (+ 0.57 $\mathrm{V}$, Fig.2A) suggesting strong adsorption of the chloride upon oxidation of the $\mathrm{I}_{2}$-TTF moieties.

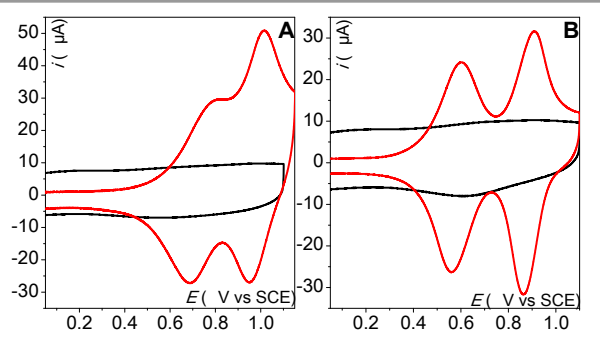

Fig. 1. CVs of unmodified (black) and modified (red) gold electrodes SAM-1a (A) and SAM-1b (B) in $0.1 \mathrm{M} \mathrm{NBu}_{4} \mathrm{PF}_{6} / \mathrm{ACN}$. $\mathrm{v}=10 \mathrm{~V} / \mathrm{s}$. 
Fig.2. CVs of SAMs
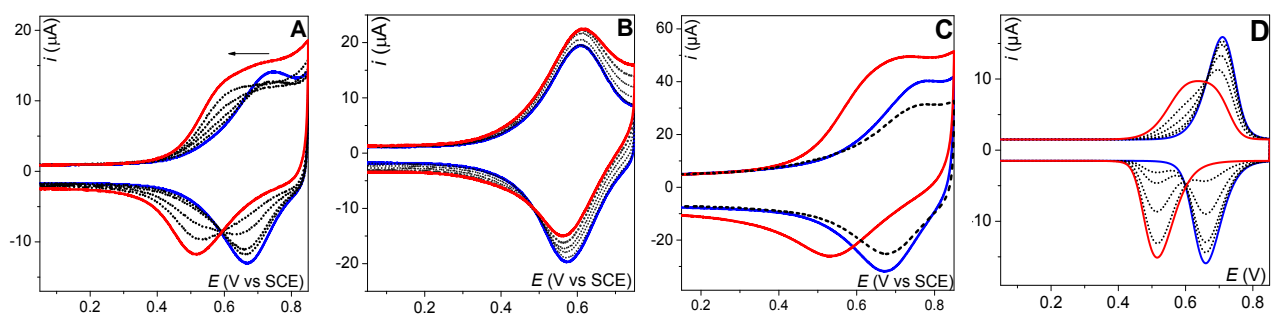

of SAM-1a (A) and SAM$\mathrm{NBu}_{4} \mathrm{PF}_{6} / \mathrm{ACN}$,

presence of increasing amounts of $\mathrm{NBu}_{4} \mathrm{Cl}$ (concentration: $0.01,0.05,0.1,0.15$ and $\left.0.2 \mathrm{mM}\right) . \mathrm{v}=10 \mathrm{~V} / \mathrm{s}$. (C) CVs of SAM-1a in $0.1 \mathrm{M} \mathrm{NBu} 4 \mathrm{PF}_{6} / \mathrm{ACN}$, in absence $(\mathrm{blue})$ and presence of $0.2 \mathrm{mM}$ of $\mathrm{NBu}_{4} \mathrm{Cl}$ (red) and after rinsing off the chloride salt (black dashed). $\mathrm{v}=10 \mathrm{~V} /$. (D) Simulated CVs for SAM-1a. (Details for the electrochemical simulation are given in ESI + ).

The fact that SAM-1b did not at all respond to chloride, even at high concentration (Fig.2B), provides evidence for predominant $X B$ interaction with SAM-1a. CVs in Figure 2A show an isobestic point at $+0.59 \mathrm{~V}$, evidencing the co-existence of two different species. The oxidation peaks are less well defined which could be due either to the simultaneous and independent $\mathrm{Cl}^{-}$ oxidation at increasing concentrations or to a purely kinetic effect.

In order to verify the first hypothesis we prepared SAM-4 containing the non-electroactive derivative $\mathbf{4}$ where TTF is replace by a phenyl group. CVs of the electrochemically inactive SAM-4 showed a significantly decreased capacitive current and no faradic current was obtained (Fig.S8, see $\mathrm{ESI}^{+}$). In the presence of chloride anions an irreversible anodic wave appeared at $+0.64 \mathrm{~V}$ (Fig.S12, see $\mathrm{ESI}^{\dagger}$ ) and can be attributed to the direct oxidation of $\mathrm{Cl}^{-}$at the modified electrode. This current is however low and can be neglected. The influence of the nature of the Lewis base was further investigated.

Addition of bromide in the solution afforded a similar response of SAM-1a with apparition of an isobestic point at $+0.59 \mathrm{~V}$ and a new oxidation peak centred at $+0.62 \mathrm{~V}$ (Fig.S10, see $\mathrm{ESI}^{+}$). These results are in accordance with the reported relative $X B$ acceptor strength of halides (Fig.S11, see $\mathrm{ESI}^{\dagger}$ ). No significant shift was observed in the presence of triflate and SAM-1a and similarly no shift was evidenced for SAM-1b in the presence of any of the investigated anions (Fig.S10-S11, see ESI ${ }^{+}$).

For demonstrating the reversibility of the binding SAM-1a was thoroughly rinsed with many solvents and immersed into a new chloride free electrolyte. CVs in Figure $2 \mathrm{C}$ show that the initial oxidation peak is recovered. The small decrease of the current intensity is attributed to partial desorption during the experiment, a common drawback of SAMs.
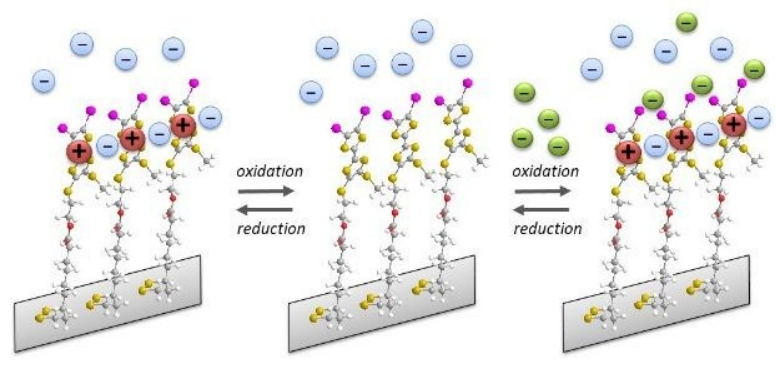

Scheme 2. Principle of electrochemically driven $\mathrm{XB}$ formation in the presence of $\mathrm{PF}_{6}$ (blue) and halides (green).
For chloride a limit of detection (LOD) of $6 \times 10^{-6} \mathrm{M}$ was estimated, based on the fitting of the calibration curve with the Langmuir model (Fig S13). The observed CVs' features and the low LOD point towards a very high affinity constant between $\mathrm{Cl}^{-}$ and the one electron oxidized SAM-1a.

Scheme 2 illustrates our mechanism proposal involving the positively charged $\mathrm{I}_{2}-\mathrm{TTF}^{+}$layer stabilized by $\mathrm{Cl}^{-}$anions arranged in positions close to the polarized iodine atoms, thus favouring $\mathrm{XB}$ formation. The supporting electrolyte anions $\left(\mathrm{PF}_{6}{ }^{-}\right)$counterbalance the created TTF cations on the surface. When adding $\mathrm{Cl}^{-}$ a supplementary stabilization via localized XB likely contributes to the formation of a complex series with a lower oxidative potential.

The evidence of predominant $X B$ interaction for SAM-1a (Fig.2D) is also supported by electrochemical simulation with Kissa-1D@ ${ }^{27}$ from the previous square scheme ${ }^{17}$ dedicated to electrochemical oxidation of I-TTF in the presence of $\mathrm{Cl}^{-}$:

$$
\begin{aligned}
& \mathrm{I}_{2}-\mathrm{TTF}_{\mathrm{Ads}} \rightleftharpoons \mathrm{I}_{2}-\mathrm{TTF}_{\mathrm{Ads}}^{+}+\mathrm{e}^{-} \quad\left(k_{\mathrm{s}}, \alpha, E_{1}^{\circ}\right) \quad \text { Eq. } 1 \\
& \mathrm{I}_{2}-\mathrm{TTF}_{\mathrm{Ads}}+\mathrm{Cl}^{-} \rightleftarrows \mathrm{I}_{2}-\mathrm{TTF} \quad \cdots \cdots \mathrm{Cl}_{\text {Ads }}^{-} \quad\left(K_{\text {red }}, k_{\mathrm{f}}\right) \quad \text { Eq. } 2 \\
& \mathrm{I}_{2}-\mathrm{TTF} \quad \cdots+\mathrm{Cl}_{\mathrm{Ads}}^{-} \rightleftharpoons \mathrm{I}_{2}-\mathrm{TTF}^{+}{ }_{1 \cdots \mathrm{Cl}^{-}}^{-} \mathrm{Ads}^{-}+\mathrm{e}^{-}\left(k_{\mathrm{s}}, \alpha, E_{2}^{\circ}\right) \quad \text { Eq. } 3 \\
& \mathrm{I}_{2}-\mathrm{TTF}_{\mathrm{Ads}}^{+}+\mathrm{Cl}^{-} \rightleftarrows \mathrm{I}_{2}-\mathrm{TTF}^{+}{ }^{+}, \mathrm{Cl}_{\mathrm{Ads}}^{-} \quad\left(K_{o x}, k_{\mathrm{f}}\right) \quad \text { Eq. } 4 \\
& \text { With } \Delta E=E_{1}^{\circ}-E_{2}^{\circ}+\frac{R T}{F} \ln \left(\frac{K_{\text {red }}}{K_{\text {ox }}}\right)
\end{aligned}
$$

Where $E_{1}^{\circ}$ and $E_{2}^{\circ}$ are redox standard potentials, $k_{\mathrm{s}}$ standard electron transfer rates, $\alpha$ the transfer coefficient, $k_{\mathrm{f}}$ forward rate constants and $K_{\mathrm{ox}(\mathrm{red})}$ equilibrium constants.

According to our previous work, ${ }^{17} k_{\mathrm{f}}$ for Eq (2) and (4) are equal to $10^{+6} \mathrm{~s}^{-1}$, a sufficiently high value for the system to be under dynamic equilibrium. $\alpha$ and $k_{\mathrm{s}}$ are equal to 0.5 and $250 \mathrm{~s}^{-1}$ respectively, in accordance with a reversible and fast electron transfer system. Electrochemical simulations with a - $160 \mathrm{mV}$ potential shift $(\triangle \mathrm{E})$ and $K_{\text {red }}=1000 \mathrm{M}^{-1}$ (Table 2$)$ are consistent with the experimental data for SAM-1a (Fig.2A) and lead to an isobestic point (Fig.2D), as found experimentally. Importantly, using such a square scheme while having one experimental observable $(\Delta \mathrm{E})$ and two unknown parameters leads only to the determination of the $K_{\text {ox }} / K_{\text {red }}$ affinity constants ratio. The $K_{\text {red }}$ values used for the simulation were those giving the best fits and allowing a satisfactory description of the $X B$ interactions obtained with SAM-1a.

It should however be noted that such values are in accordance with the organization of multiple XB-donors on a well-defined 
Table 2. Affinity constants (in $\mathrm{M}^{-1}$ ) toward $\mathrm{Cl}^{-}$for compounds in solution and on surface.

\begin{tabular}{cccc}
\hline & $K_{\text {red }}$ & $K_{\text {ox }}$ & $K_{\text {ox }} / K_{\text {red }}$ \\
\hline 1a $^{[a]}$ & 3 & 800 & $267 \pm 40$ \\
3a $^{[a]}$ & 10 & 1200 & $120 \pm 25$ \\
SAM-1a $^{[b]}$ & $1000[c]$ & 565065 & 565
\end{tabular}

[a] in 30\% ACN / 70\% DMF; [b] ACN; [c] estimated from electrochemical simulation.

surface, leading to a polytopic receptor able to strongly bind anions (surface chelate effect). ${ }^{28}$

In conclusion we have designed and quantified electrochemically driven charge-assisted $X B$ at a surface confined system. There is strong evidence for $X B$ being the dominant noncovalent interaction in the investigated system. The particular high and selective binding enhancement towards halide anions association with the oxidized SAM points to a strong surface chelate effect of the assembled 2D material. Such effect could be used for the future conception and development of supramolecular assemblies for selective anion capture/release, sensors and organic electronics devices.

\section{Conflicts of interest}

There are no conflicts to declare.

\section{Notes and references}

1 a) F. Schreiber, Prog. Surf. Sci., 2000, 65, 151; b) J. C. Love, L. A. Estroff, J. K. Kriebel, R. G. Nuzzo and G. M. Whitesides, Chem. Rev., 2005, 105, 1103; c) E. Prats-Alfonso and F. Albericio, J. Mater. Sci., 2011, 46, 7643; d) A. L. Eckermann, D. J. Feld, J. A. Shaw and T. J. Meade, Coord. Chem. Rev., 2010, 254, 1769; e) D. Mandler and S. Kraus-Ophir, J. Solid State Electrochem., 2011, 15, 1535.

2 S. Zhang, C. M. Cardona and L. Echegoyen, Chem. Commun., 2006, 4461.

3 a) R. Elshafey, M. Siaj and M. Zourob, Anal. Chem., 2014, 86, 9196; b) N. H. Jabarullah, E. Verrelli, C. Mauldin, L. A. Navarro, J. H. Golden, L. M. Madianos and N. T. Kemp, Langmuir, 2015 31, 6253; c) R. P. Liang, X. C. Tian, P. Qiu and J. D. Qiu, Anal. Chem., 2014, 86, 9256; d) X. Mu, A. Gao, D. Wang and P. Yang, Langmuir, 2015, 31, 2922.

4 a) J. L. Sessler and J. M. Davis, Acc. Chem. Res., 2001, 34, 989; b) M. J. Langton and P. D. Beer, Acc. Chem. Res., 2014, 47 1935; c) G. W. Gokel, W. M. Leevy and M. E. Weber, Chem. Rev., 2004, 104, 2723; d) N. Busschaert, C. Caltagirone, W. Van Rossom and P. A. Gale, Chem. Rev., 2015, 115, 8038.

5 S. Flink, F. C. J. M. van Veggel and D. N. Reinhoudt, Adv. Mater., 2000, 12/18, 1315

6 a) D. P. Cormode, A. J. Evans, J. J. Davis and P. D. Beer, Dalton Trans., 2010, 39, 6532; b) P. D. Beer, J. J. Davis, D. A. DrillsmaMilgrom and F. Szemes, Chem. Commun., 2002, 1716; c) N. H. Evans and P. D. Beer, Angew. Chem. Int. Ed., 2014, 53, 11716 d) J. J. Gooding, F. Mearns, W. Yang and J. Liu, Electroanalysis, 2003, 15, 81; e) H. T. Ngo, X. Liu and K. A. Jolliffe, Chem. Soc. Rev., 2012, 41, 4928; f) R. M. Crooks and A. J. Ricco, Acc. Chem. Res., 1998, 31, 219; g) R. C. Major and X.-Y. Zhu, J. Am. Chem. Soc., 2003, 125, 8454.

7 K. Ariga and T. Kunitake, Acc. Chem. Res., 1998, 31, 371.

8 G. G. Desiraju, P. S. Ho, L. Kloo, A. C. Legon, R. Marquardt, P. Metrangolo, P. A. Politzer, G. Resnati and K. Rissanen, Pure Appl. Chem., 2013, 85, 1711.
9 a) L. C. Gilday, S. W. Robinson, T. A. Barendt, M. J. Langton, B. R. Mullaney and P. D. Beer, Chem. Rev., 2015, 115, 7118; (b) G. Cavallo, P. Metrangolo, R. Milani, T. Pilati, A. Priimagi, G. Resnati and G. Terraneo, Chem. Rev., 2016, 116, 2478.

10 P. Politzer and J. S. Murray, ChemPhysChem, 2013, 14, 278.

11 M. Boterashvili, T. Shirman, S. R. Cohen, G. Evmenenko, P. Dutta, P. Milko, G. Leitus, M. Lahav and M. E. van der Boom, Chem. Commun., 2013, 49, 3531.

12 T. Shirman, T. Arad and M. E. van der Boom, Angew. Chem. Int. Ed., 2010, 122, 938.

13 M. Albers, R. Milani, K. Tappura, T. Munter, G. Resnati and P. Metrangolo, Int. J. Mol. Sci., 2013, 14, 3500.

14 A. Vanderkooy and M. S. Taylor, J. Am. Chem. Soc., 2015, 137 5080.

15 a) W. B. Swords, S. J. C. Simon, F.r G. L. Parlane, R. K. Dean, C. W. Kellett, K. Hu, G. J. Meyer and C. P. Berlinguette, Angew. Chem. Int. Ed., 2016, 55, 5956; b) S. J. C. Simon, F. G. L. Parlane, W. B. Swords, C. W. Kellett, C. Du, B. Lam, R. K. Dean, K. Hu, G. J. Meyer and C. P. Berlinguette, J. Am. Chem. Soc., 2016, 138, 10406.

16 S. Groni, T. Maby-Raud, C. Fave, M. Branca and B. Schöllhorn, Chem. Commun., 2014, 50, 14616.

17 a) R. Oliveira, S. Groni, C. Fave, M. Branca, F. Mavre, D. Lorcy, M. Fourmigué and B. Schöllhorn, Phys.Chem.Chem.Phys., 2016, 18, 15867; b) R. Oliveira, S. Groni, A. Vacher, F. Barrière, D. Lorcy, M. Fourmigué, E. Maisonhaute, B. Schöllhorn and C. Fave, ChemistrySelect., 2018, 3, 8874.

18 a) J. Y. C. Lim, M. J. Cunningham, J. J. Davis and P. D. Beer, Chem. Commun., 2015, 51, 14640; b) J. Y. C. Lim and P. D. Beer, Eur. J. Inorg. Chem., 2017, 220.

19 G. Creste, S. Groni, C. Fave, M. Branca and B. Schöllhorn, Faraday Discussions, 2017, 203, 301.

20 a) A. J. Moore, L. M. Goldenberg, M. R. Bryce, M. C. Petty, A. P. Mokman, C. Marenco, J. Yarwood, M. J. Joyce and S. N. Port, Adv. Mater., 1998, 10, 395; b) S. Zhang, C. M. Cardona and L. Echegoyen, Chem. Commun., 2006, 4461; c) J. Lyskawa, M. Oçafrain, G. Trippé, F. Le Derf, M. Sallé, P. Viel and S. Palacin, Tetrahedron, 2006, 62, 4419; d) A. J. Moore, L. M. Goldenberg, M. R. Bryce, M. C. Petty, J. Moloney, J. A. K. Howard, M. J. Joyce and S. N. Port, J. Org. Chem., 2000, 65, 8269.

21 a) L. Chung-Chiun, Handbook of Chemical and Biological Sensors, Taylor \& Francis, 1996; b) R.M. Duke, E. B. Veale, F. M. Pfeffer, P. E. Kruger and T. Gunnlaugsson, Chem. Soc. Rev., 2010, 39, 3936; c) P. A. Gale and C. Caltagirone, Chem. Soc. Rev., 2015, 44, 4212.

22 a) R. Sahli, C. Fave, N. Raouafi, K. Boujlel, B. Schollhorn and B. Limoges, Langmuir, 2013, 29, 5360; b) D. Capitao, B. Limoges, B. Schöllhorn and C. Fave, Electrochimica Acta, 2017, 257 165; c) D. Capitao, R. Sahli, N. Raouafi, B. Limoges, C. Fave and B. Schöllhorn, ChemElectroChem., 2016, 3, 1422.

23 J. Lieffrig, O. Jeannin, A. Vacher, D. Lorcy, P. Auban-Senzier and M. Fourmigué, Acta Cryst., 2014, B70, 141.

24 S. Matsumoto, W. Matsuda, H. Fueno, Y. Misaki and K. Tanaka, Synthetic Metals, 2005, 153, 429.

25 J. Massue, N. Bellec, S. Chopin, E. Levillain, T. Roisnel, R. Clérac and D. Lorcy, Inorg. Chem., 2005, 44, 8740.

26 a) P. Y. Blanchard, O. Alévêque, S. Boisard, C. Gautier, A. ElGhayoury, F. Le Derf, T. Breton and E. Levillain, Phys.Chem.Chem.Phys., 2011, 13, 2118; b) J. CasadoMontenegro, M. Mas-Torrent, F. Oton, N. Crivillers, J. Veciana and C. Rovira, Chem Commun., 2013, 49, 8084.

27 C. Amatore, O. Klymenko and I. Svir, Electrochem. Commun., 2010, 12, 1170.

28 R. C. Major and X.-Y. Zhu, J. Am. Chem. Soc., 2003, 125, 8454. 


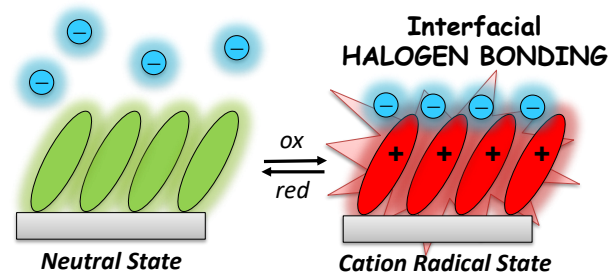

The concept of anion detection via a reversible electrochemically driven charge-assisted Halogen Bonding in solution was transferred on the surface. 